\title{
Response to: Platelet indices in patients with unexplained recurrent miscarriage; related factors should be considered
}

\author{
Ülkü Mete Ural · Yeşim Bayoğlu Tekin · Gülşah Balik • \\ Figen Kir Şahin · Sabri Çolak
}

Published online: 13 June 2014

(C) Springer-Verlag Berlin Heidelberg 2014

\section{Dear Colleague,}

Thank you for your review [1] and comments regarding our article [2]. Assessment of MPV has been made within $1 \mathrm{~h}$ using EDTA tubes. Regarding your question on the body mass index, smoking status, metabolic syndrome and blood cholesterol levels in our series, cases investigated were nonsmokers with no reported co-morbidities such as hypercholesterolemia, metabolic syndrome or obesity. Cases with body mass indices $>29.9$ had already been excluded from the study.

Despite these efforts to have conditions prone to influence platelet morphology and function, we state that it may not be possible to have all parameters under control. Anyway, we hope that our study will pioneer further studies for a beter understanding of physiopathology of unexplained recurrent miscarriage.
Conflict of interest None.

\section{References}

1. Varol E (2014) Platelet indices in patients with unexplained recurrent miscarriage; related factors should be considered. Arch Gynecol Obstet. doi:10.1007/s00404-014-3299-0

2. Mete Ural Ü, Bayoğlu Tekin Y, Balik G, Kir Şahin F, Çolak S (2014) Could platelet distribution width be a predictive marker for unexplained recurrent miscarriage? Arch Gynecol Obstet. doi:10.1007/s00404-014-3192-x

Ü. Mete Ural $(\bowtie) \cdot$ Y. Bayoğlu Tekin · G. Balik · F. Kir Şahin ·

S. Çolak

Department of Obstetrics and Gynecology, Recep Tayyip

Erdoğan University, School of Medicine, Rize, İslampaşa Mah

53100, Turkey

e-mail: ulkumete2004@yahoo.com 